\title{
OPERATION MODE AND EFFECT TEST OF RURAL REVITALIZATION PROMOTED BY FINANCIAL INCLUSION BASED ON A CASE STUDY OF YUEQING OF ZHEJIANG
}

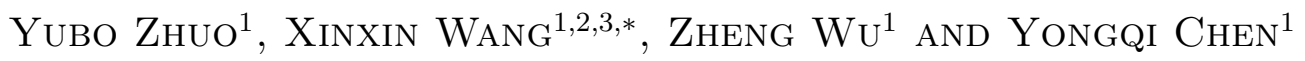

\begin{abstract}
Financial inclusion is a powerful push to realize the strategy of rural revitalization which is the "compass" of the work of agriculture, rural areas and farmers in the new era. The Strategy of Promoting Rural Revitalization by Financial Inclusion has been practiced in some areas, but there is a lack of the effect of practice and the summary of successful modes in academic researches. In this paper, taking Yueqing, Zhejiang Province, the pioneer of financial inclusion, as an example, the "Yueqing mode" of financial inclusion promoting rural revitalization was discussed based on the grounded theory, and factor analysis and multiple linear regression were further used from the perspective of residents' subjective perception to test the actual effect of "Yueqing mode". The results show that financial inclusion can actively promote the implementation of rural revitalization strategy, which is mainly reflected in the improvement of the living environment and quality of life.
\end{abstract}

Mathematics Subject Classification. 62P20.

Received November 19, 2019. Accepted February 5, 2020.

\section{INTRODUCTION}

In the report of the 19th National Congress of the Communist Party of China and the national financial work conference, General Secretary Xi Jinping emphasized on building a financial inclusion system for many times, strengthening financial services for small and micro businesses, agriculture, rural areas and farmers and remote areas, and pointed out that the strategy of "Rural Revitalization" is the guiding principle for the work of agriculture, rural areas and farmers in the new era $[10,11]$.

According to the Opinions of the CPC Central Committee and the State Council on the implementation of Rural Revitalization Strategy issued in January 2018, rural revitalization is a term which can be summarized into 5 connotations: industrial prosperity, ecological livability, rural civilization, effective governance and affluent living [14]. Huang Zuhui believed that in the process of implementing the strategy of rural revitalization, it is necessary to take affluent living as the fundamental goal, closely integrate rural civilization with effective

Keywords. Rural revitalization, effect test, factor analysis, linear regression, Yueqing.

1 School of Economics, Zhejiang University of Finance and Economics (ZUFE), Zhejiang, P.R. China.

2 Center for Regional Economy and Integrated Development, Zhejiang University of Finance and Economics (ZUFE),

Zhejiang, P.R. China.

3 Center for Economic Theory and Sustainable Development Studies, Zhejiang University of Finance and Economics (ZUFE), Zhejiang, P.R. China.

${ }^{*}$ Corresponding author: xxwang@zufe.edu.cn 
governance, effectively promote the construction of rural civilization through governance, and improve the level of rural moral governance through the construction of rural civilization. Moreover, it is necessary to combine industrial prosperity with ecological livability, so that ecological livability is not only an important feature of rural people's life, but also an important symbol of industrial prosperity [5]. Many scholars have also pointed out that industrial prosperity is the key point of rural revitalization and the key to the successful implementation of rural revitalization strategy. Summing up the views and practice modes of scholars, it can be concluded that to achieve industrial prosperity, the focus should be shifted to the issues of agriculture, rural areas and the development of agricultural industry chain $[12,19,21]$.

The document Promoting the Development Plan of Financial Inclusion (2016-2020) issued by the State Council points out that the principle of combining government guidance with market leading should be followed to improve basic financial services [13]. However, it is difficult for the market to promote the basic financial services in remote mountainous areas and rural areas at this stage, so most of the basic financial services there are dominated by the government. From the perspective of specific modes, some regions domestic and abroad have practiced some modes of promoting rural revitalization by financial inclusion. The National Agricultural Bank of Senegal drafted financial contracts with farmers on production and sales, which reduced food insecurity, increased labor productivity to a certain extent through incentive system, and promoted the development of agriculture [9]. Yurui Li proposed to let rural elites participate in the political ecology of rural development to achieve effective governance [7]. In Ethiopia, microfinance institutions and financial services companies lend moderately to farmers and organize special agricultural project training to promote the development of agricultural technology to promote the prosperity of agricultural industry [1]. In Ganzhou, it is planned to take financial inclusion as an opportunity to create a new pattern of industrial prosperity" by innovating credit products, enriching and innovating agricultural insurance products, and deepening the reform of rural collective property rights system [16]. In Huangxi village, Jiangxi Province, the mode of "giving a farmer land rights at the form of shares" was adopted to promote the prosperity of agricultural industry to boost the rural revitalization [2]. In Japan, there is a mode of rural economic revitalization driven by rural civilization in which rural art festival activities are used to strengthen local values and stimulate economic development through the activities of non-governmental organizations [17].

However, in the domestic mode of Promoting Rural Revitalization by Financial Inclusion, it only involves a single aspect of the connotation of rural revitalization, and there is no comprehensive summary of its five connotations. Although the mode of Promoting Rural Revitalization by Financial inclusion in foreign countries can provide China with certain reference, its applicability is weak due to different national conditions. In addition, because the connotation of rural revitalization involves many levels, the existing indicator system cannot effectively and reasonably test its operation effect. Moreover, in the existing literature, there is a lack of empirical research on the effect of financial inclusion on rural revitalization. In this paper, through summarizing and refining the mode of Yueqing rural commercial bank, we find its mode can greatly enhance local people's living environment and life quality. Firstly, typical areas and villages were selected to analyze the promotion effect on the five connotations, and further a referential indicator system was established based on factor analysis, and finally the effectiveness of financial inclusion to promote rural revitalization was tested through the intuitive experience data of residents.

The following structure is arranged as follows: the second part introduces the research methods, the selection of research sites and the acquisition of samples; the third part discusses the mode of promoting rural revitalization by financial inclusion, which is based on the qualitative case analysis of grounded theory; in the fourth part, an evaluation system of rural revitalization strategy will be constructed from the subjective perspective of villagers by using factor analysis; in the fifth part, regression analysis is further used to explore the effect of financial inclusion in promoting rural revitalization; finally, the corresponding countermeasures and suggestions are put forward. 


\section{RESEARCH METHODS AND DATA}

To explore the mode of rural revitalization promoted by financial inclusion in rural areas, on the one hand, this paper uses qualitative analysis method, basing on the analysis idea of grounded theory, we selected typical cases to collect first-hand data through investigation and interview. By using the data, the mode of financial inclusion promoting rural revitalization is discussed from the five connotations of rural revitalization. On the other hand, the quantitative analysis, factor analysis and regression analysis are used to test the effect of financial inclusion on rural revitalization from the perspective of subjective perception of micro subjects.

In the document Opinions of the Central Committee of the Communist Party of China and the State Council on the Implementation of the Strategy of Rural Revitalization, it is pointed out that the implementation of rural revitalization should be based on opening up investment and financing channels, strengthening the investment guarantee of rural revitalization. Then, it is clearly pointed out in the document that the reform of rural credit cooperatives should be promoted, the status and quantity of county legal persons of rural credit cooperatives should be kept stable, the access conditions of rural banks should be improved, and the local legal person financial institutions should serve the rural revitalization well. Formerly known as Zhejiang Rural Credit Cooperatives, Zhejiang Rural Credit Union (ZJRC), which has been at the forefront of financial inclusion development in Zhejiang Province, assisted China Financial Inclusion Research Institute of Renmin University of China in completing Monitoring Report on the Development of Financial Inclusion in China (2017 Zhejiang). The report points out that financial inclusion level in Zhejiang has reached the international leading level. In the problem that it is not easy for rural residents to borrow money, Zhejiang has made unique and outstanding achievements by establishing a credit system for rural residents and flexibly turning real estate into mortgage assets. At present, 9.66 million farmers have established credit files, and 8.21 million credit users have been assessed [22], so that rural residents can truly experience the convenience of credit loans. In addition, in order to further solve the current situation of loan difficulty, Zhejiang has also innovated and launched the loan mode of unsecured micro credit. By the end of 2016, ZJRC alone had issued 113.3 billion yuan of microcredit, providing microcredit services for nearly 1.24 million farmers. In terms of financial service coverage, Zhejiang has achieved more than $80 \%$ coverage of new outlets (franchises) in small and micro enterprises, suburban areas, and rural areas. It has promoted and popularized mobile financial service terminals such as POS machines in areas without outlets, and has focused on the pursuit of rural financial services without dead ends. At present, Zhejiang has a wide range of financial services with good availability and high satisfaction, leading in the country. Therefore, Zhejiang Province was selected as the research area. In the selection of counties and cities, Yueqing is located in the southeast coast of Zhejiang Province, and its geographical location is shown in Figures 1 and 2. Yueqing is a county-level city under the jurisdiction of Zhejiang Province, which has been selected as one of the top 100 cities with comprehensive competitiveness of county economy, top 100 cities with investment potential, top 100 best commercial cities in mainland China in 2018, and top 30 best county-level cities in China [6]. In terms of economic indicators, its GDP in 2017 was 94.745 billion yuan, with a growth rate of $9.1 \%$, ranked the 10 th among 61 counties (cities and districts) in the province, and its growth rate ranked the 8th [18].

Yueqing Rural Commercial Bank is a local joint-stock commercial bank and one of the 11 independent rural commercial banks under the jurisdiction of Zhejiang Rural Credit Cooperatives, which owns a share capital of 1.103 billion yuan. Yueqing Rural Commercial Bank takes the leading position in the banking industry in terms of deposit, agricultural related loan, small and micro loan, etc., and its asset quality and operating efficiency rank first in the province. It leads the whole province in promoting rural development and rural revitalization by financial inclusion. Adhering to the principle of "providing services to small and micro businesses, and agriculture, rural areas, and rural residents", Yueqing Rural Commercial Bank has taken a "small and beautiful" way of differentiated operation. Therefore, its financial inclusion mode has been written into the Chinese financial inclusion white paper. Finally, Yueqing City was selected as the main site of the survey. Six representative administrative villages out of the 911 administrative villages in 21 towns, 10 townships and 8 sub-districts of Yueqing City were chosen for the survey. 


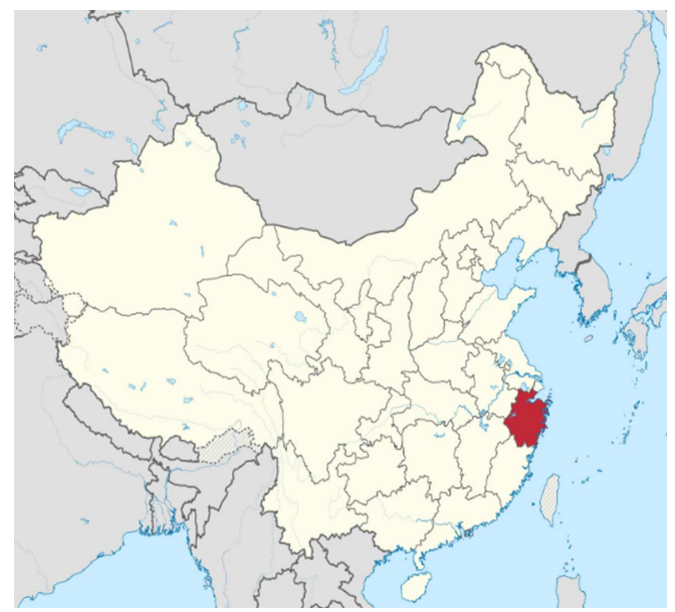

Figure 1. Location of Zhejiang in China.

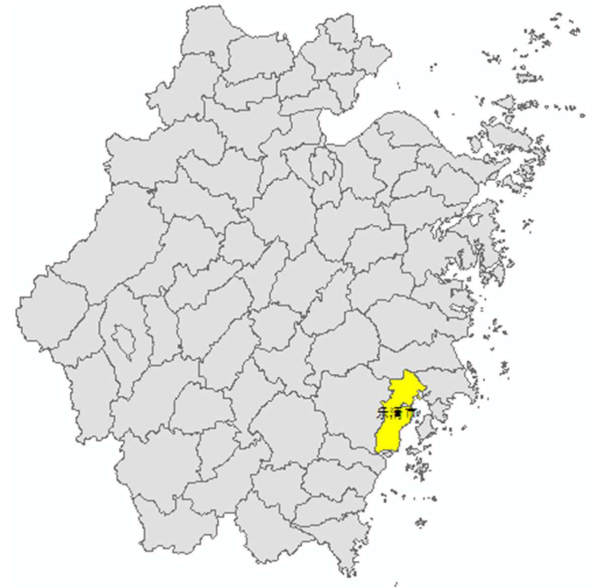

Figure 2. Location of Yueqing in Zhejiang.

In the investigation, the rural grass-roots units were deepened and visited on the spot. In terms of places, the main houses, senior activity centers and other places of different levels were selected. Before the survey, the area was evenly selected on the map. The randomness was mainly to ensure gender balance and age randomness. In each sampling administrative village, about 10 valid questionnaires were distributed and a high-quality interview was completed. Finally, 150 valid questionnaires and 7 valid interview records were formed.

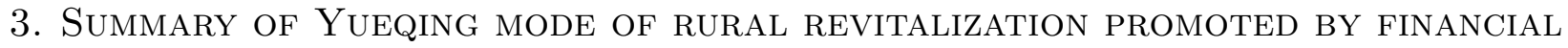 INCLUSION}

\subsection{Credit granting and low interest rate loan promote industrial prosperity}

Chen et al. pointed out through theoretical analysis that the rural revitalization strategy should emphasize the priority development of agriculture and rural areas, and the focus should be changed from traditional agriculture to the whole rural area [3]. Aiming at the overall development of rural areas, Yueqing Rural Commercial Bank promotes the prosperity of the industry by improving the availability and timeliness of loans for agriculture, rural areas and farmers. On the one hand, the loan coverage and lending efficiency are improved in the practice of "village credit granting". Yueqing Rural Commercial Bank sends special personnel to each village for credit evaluation, and provides specific credit lines for each villager in the village, so as to provide them with quick loans when they need funds. Such methods greatly facilitate the development of the industry. In terms of "village credit granting", Yueqing Rural Commercial Bank has established 83 credit demonstration villages in the local area, completed electronic information registration for 911 farmers in administrative villages, and achieved $100 \%$ coverage of rural finance. In terms of poverty alleviation, Yueqing Rural Commercial Bank provides loans to $1 / 3$ of local farmers, undertakes $4 / 5$ of agricultural related loans, and provides $100 \%$ of local policy-oriented poverty alleviation loans and poverty alleviation work in weak villages.

Taking the development of watermelon industry in Dalingtou Village, Xianxi Town promoted by financial inclusion as an example. In the 1990s, Dalingtou Village was a poor village in Yueqing District, with an average annual income of less than 3000 yuan. At that time, there were 97 families and 300 people in the village, and the only livelihood skill was the planting technology. There was a large-scale watermelon farmer in the village, but he had no venture capital. In 2003, with the help of Yueqing Rural Commercial Bank, the farmer obtained his first low interest rate loan and invested it in the development of his industry, making the first 
barrel of gold. After that, the watermelon farmer led the villagers to work on agricultural production. Yueqing Agricultural Commercial Bank sent special personnel to investigate the agricultural base of Dalingtou Village every year for more than ten years, customized diversified and effective financial services for it, and finally formed a cooperation mode of "cooperative + farmer + poverty alleviation low interest rate loan". In addition, Yueqing Rural Commercial Bank also granted credits to the entire Dalingtou Village, giving villagers appropriate loan lines, so that they can get financial help quickly without mortgage when they need it, and facilitating villager's agricultural production activities. Up to now, more than $80 \%$ of families in Dalingtou Village of Xianxi Town have obtained loan support. The annual loan amount of Yueqing rural commercial bank in the village reached 30 million yuan, the average household loan was more than 300000 yuan, and the interest rate of poverty alleviation discount loan was less than $6 \%$. Accordingly, thanks to the help of the poverty alleviation discount loan, the average annual income of the villagers in Dalingtou Village has increased 100 times compared with 1997.

\subsection{Targeted loan and environmental improvement realize ecological livability}

Rural infrastructure is the essential part of ecological livability, and the restoration of rural ecological environment is the premise of rural livability [20]. On the basis of the self-improvement of the village environment by villagers, Yueqing Rural Commercial Bank gives some villages targeted poverty alleviation loans to build and develop guesthouse industry, so as to realize the ecological livability of the village.

Xianshengmen village in Longxi township is an example. Xianshengmen village situates in the north side of Yandang Mountain Scenic Area, a national 5A scenic area. It is a poor village with weak economy, whose collective economy was lacking, and the per capita income of the villagers was only 12000 yuan. There are scenic spots such as Longliu, Sanshui Cliff, Xianyan Cave, Xianzhang Peak, Fairy Peak, Fairy Pool, Toutian 18 Holes and Lion Rock, etc. around the village. Due to its gorgeous scenery, it had been taken on the spot by the drama group of "Legend of Shooting Heroes" and "Nirvana in Fire". However, due to its lack of economic strength, it had not been able to develop scenic spots around the village. Realizing the ecological environment is the foundation of tourism development, villagers actively improved the infrastructure such as greening, roads, etc., and carried out environmental remediation, assigned environmental managers, and formulated environmental and ecological management norms after receiving the targeted loan from Yueqing Rural Commercial Bank. After the improvement of the environment, the villagers of Xianshengmen Village, with the support of funds, set up a guesthouse cooperative, adapted measures to local conditions, transformed the old houses into guesthouses, gave full play to the advantages of natural resources, attracted about 3000-4000 tourists every day, and increased the source of economic income for the villagers. By renovating, protecting, greening, restoring the ecology, and setting up the basic facilities such as accommodation according to local conditions, Xianshengmen Village not only protects the ecological resources to the maximum extent, but also creates a livable environment for the villagers.

\subsection{Model publicity and moral loan promote rural civilization}

Rural civilization is the link between material civilization and spiritual civilization, and the core is to strengthen rural cultural construction [15], which is an important carrier of the development of rural civilization. In terms of cultural construction, Yueqing Rural Commercial Bank has established a "good person assistance mechanism" to provide moral model personnel with preferential loan procedures and loan interest rates.

Taking the issue of "moral loans" to promote moral fashion as an example, Xu Zhiying, a Yueqing man, was named "The most beautiful Yueqing man" because he set his factory as a placement place for drug control and education in Yueqing, helping the rehabilitation of drug addicts. In line with the application standard of 
moral loan, Xu Zhiying applied to Yueqing Rural Commercial Bank for a "moral loan" of 300000 yuan with an annual interest of only $4 \%$ to turn around the factory capital, which helped the factory survive the crisis. For those who have obtained moral models above the municipal level, they can obtain credit loans of 500000 yuan. "Moral loan" not only encourages the moral model similar to Xu Zhiying to continue to do good, but also further promotes the moral fashion.

\subsection{Harvest station and platform cooperation realize effective governance}

Rural governance is the foundation of national governance. It not only achieves the goal of national governance, but also forms a relatively stable social structure in the process of dealing with various affairs in different groups, classes and fields in rural society [8]. While promoting the rural financial coverage, the promotion of basic financial services can also bring convenience to the implementation of government affairs.

Taking the promotion of the "harvest station" of Yueqing Rural Commercial Bank as an example, formerly known as agricultural aid service station, it aims to enable farmers in remote mountainous areas to enjoy basic financial services. However, in recent years, the comprehensive transformation of agricultural service stations has been gradually carried out. On the basis of the rural basic financial coverage rate of $100 \%$, more than 1200 agricultural service stations have been gradually upgraded to "harvest stations", and the service scope has been extended to the consultation and agency of administrative affairs such as basic living allowance, settlement, housing construction, certificate handling, birth control, etc. Among them, the most basic social security business in government affairs accounts for more than $60 \%$. The operation of "harvest stations" strengthened the data mining ability of Yueqing Rural Commercial Bank. Moreover, in the processing of existing data, Yueqing Rural Commercial Bank actively cooperates with government departments and other platforms to share data, further strengthening the value of customer data. Internally, Yueqing rural commercial bank integrates, digs and analyzes the existing information of customers to provide valuable information for scientific positioning of customers and precise marketing. Externally, Yueqing Rural Commercial Bank accesses external data, uses provincial platform to strengthen cooperation between banking and government, deepens cooperation with agricultural offices, social security departments, housing fund centers, agricultural cooperative associations and other units, which enhances the effectiveness of grassroots data acquisition and the convenience of grassroots government processing.

\subsection{Affluent living achieved by combined action of four levels}

Affluence is the starting point, destination, and also the goal of rural revitalization. The prosperity of the watermelon industry has increased the income of the villagers in Dalingtou village by 100 times in 20 years; the ecological livability has not only improved the ecological environment of Xianshengmen village, but also promoted the development of the guesthouse industry, bringing new income to the villagers. The connotation of life affluence can be not only material life affluence, but also spiritual life affluence. Effective governance provides convenience for the management of various government affairs, and it is easier to provide satisfaction to villagers compared with the complicated procedures in the past; rural civilization provides villagers with different spiritual and cultural activities and enriches their lives with the help of financial inclusion. Whether it is industrial prosperity, ecological livability, rural civilization or effective governance, it is ultimately to let finance return to the essence of "human" to achieve "human" life prosperity and finally achieve rural revitalization. The four connotations of financial inclusion are industrial prosperity, ecological livability, rural civilization and effective governance, which jointly promote the realization of life-prosperity (Fig. 3). 


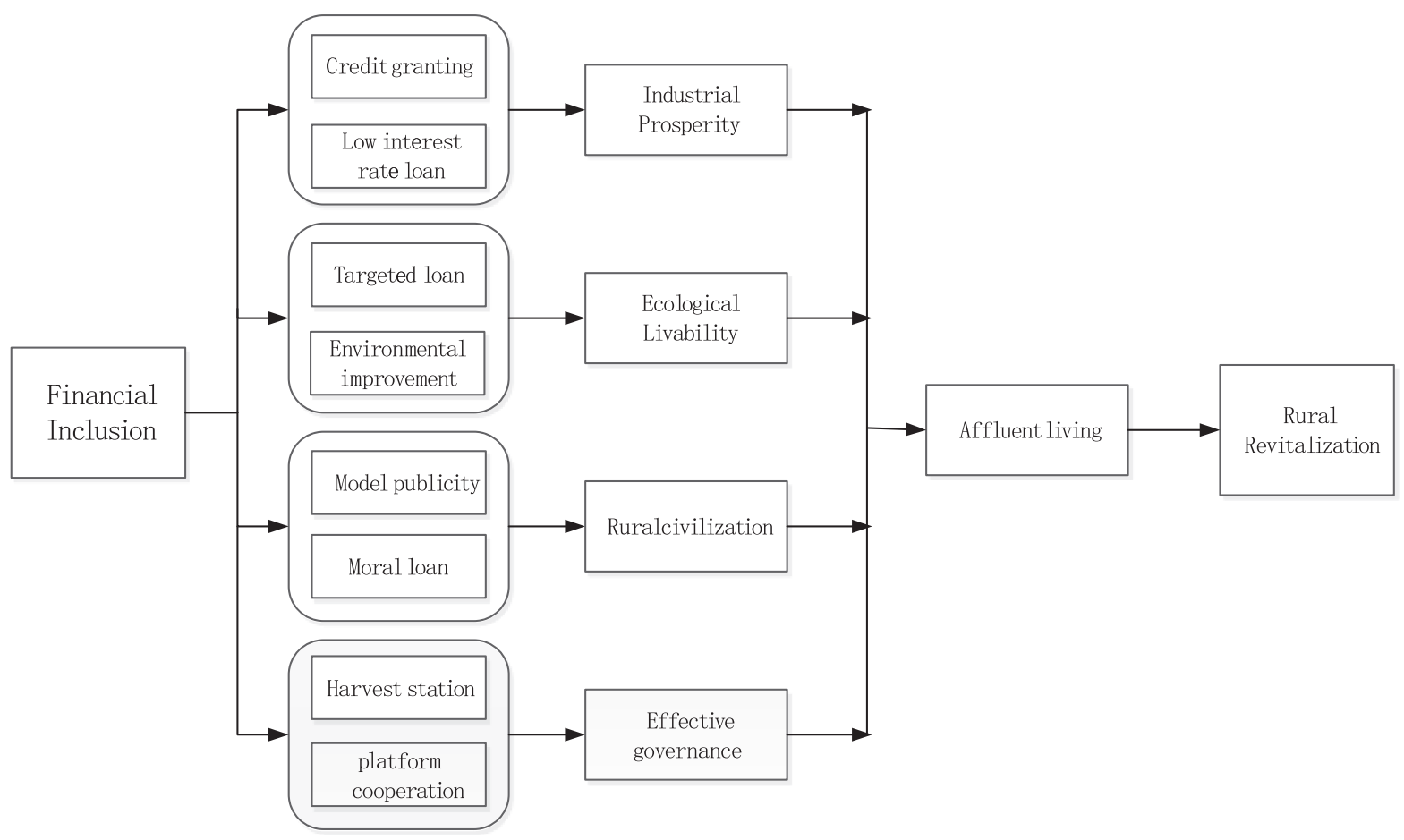

FiguRE 3 . The mode of rural revitalization promoted by financial inclusion.

\section{Construction of indicator System FOR RURAl Revitalization Based on the SUBJECTIVE FEELINGS OF RURAL RESIDENTS}

In order to have a better effect test, qualitative analysis was done. On this basis of case interview, the questionnaire data was afterwards collected to analyze the implementation of local rural revitalization strategy and financial inclusion in Yueqing and explore the relationship between them. The questionnaire was mainly divided into three parts: basic situation, rural revitalization and financial inclusion. In the part of rural revitalization, starting with the five connotations of rural revitalization, the corresponding questions were set up, and the results were obtained through a five-point scale. In the part of financial inclusion, according to the research done by Xia Gao [4], the corresponding questions were designed from three dimensions: the quality of formal financial services, the use and the availability of financial services [4]. Then the samples were analyzed by factor analysis to extract the key factors and construct the evaluation indicator system. Finally, in order to better distinguish and compare the results of the implementation of rural revitalization in each village, factor analysis was used in this paper to further analyze the scale, so as to get a valid, reliable evaluation system for the implementation of rural revitalization strategy at the villager's subjective level. In order to evaluate the implementation of rural revitalization strategy, factor analysis was carried out by SPSS20.0. Table 2 shows that there are 15 indicators to evaluate the implementation of the rural revitalization strategy, with 1-5 points for strongly disagreed, disagreed, neutral, rather agreed and totally agreed respectively. Therefore, the standardization of 15 indicators was carried out first, followed by KMO test and Bartlett sphericity test. The test results were that the value of KMO test was 0.827, the chi square value of Bartlett test was 614.937 , and the significance level of test was 0.000 . To better illustrate the indicator, we set a Table 1 to explain what does each question means. 
TABLE 1. Question explanation.

\begin{tabular}{ll}
\hline \hline A1 & Your village has introduced the rural revitalization strategy to you \\
A2 & You understand the specific meaning of the strategy \\
A3 & To implement the strategy, some actions have been taken in your village \\
A4 & Rural industry in your village is more developed then before \\
A5 & Your family has reached a well-off level \\
A6 & The quality of your family life has improved in the past two years \\
A7 & Your village is rich on the whole \\
A8 & The quality of life of all the villagers in your village has improved in the past two years \\
A9 & Good environmental governance \\
A10 & The environmental governance in your village has improved in the past two years \\
A11 & Strong cultural atmosphere \\
A12 & The neighborhood in your village has become more harmonious in recent years \\
A13 & Village cadres can deal with all kinds of problems and disputes in accordance with the law \\
A14 & Good democracy at the grassroot level \\
A15 & Implementing the rural revitalization strategy has positive meaning \\
\hline
\end{tabular}

TABLE 2. Rural revitalization scale.

\begin{tabular}{lrrrrr}
\hline \hline Title & Totally disagree & Not quite agree & Neutral opinion & Quite agree & Totally agree \\
\hline A1 & $12.00 \%$ & $5.33 \%$ & $14.67 \%$ & $8.67 \%$ & $49.33 \%$ \\
A2 & $17.33 \%$ & $18.67 \%$ & $16.00 \%$ & $25.33 \%$ & $22.67 \%$ \\
A3 & $4.00 \%$ & $4.00 \%$ & $9.33 \%$ & $36.00 \%$ & $46.67 \%$ \\
A4 & $5.33 \%$ & $17.33 \%$ & $21.33 \%$ & $30.67 \%$ & $25.33 \%$ \\
A5 & $6.67 \%$ & $9.33 \%$ & $12.00 \%$ & $30.67 \%$ & $41.33 \%$ \\
A6 & $2.67 \%$ & $2.67 \%$ & $10.67 \%$ & $24.00 \%$ & $60.00 \%$ \\
A7 & $8.00 \%$ & $12.00 \%$ & $16.00 \%$ & $40.00 \%$ & $24.00 \%$ \\
A8 & $4.00 \%$ & $2.67 \%$ & $10.67 \%$ & $40.00 \%$ & $42.67 \%$ \\
A9 & $2.67 \%$ & $4.00 \%$ & $6.67 \%$ & $42.67 \%$ & $44.00 \%$ \\
A10 & $2.67 \%$ & $2.67 \%$ & $5.33 \%$ & $30.67 \%$ & $58.67 \%$ \\
A11 & $6.67 \%$ & $8.00 \%$ & $10.67 \%$ & $29.33 \%$ & $45.33 \%$ \\
A12 & $2.67 \%$ & $4.00 \%$ & $6.67 \%$ & $33.33 \%$ & $53.33 \%$ \\
A13 & $4.00 \%$ & $6.67 \%$ & $8.00 \%$ & $34.67 \%$ & $46.67 \%$ \\
A14 & $5.33 \%$ & $0.00 \%$ & $4.00 \%$ & $20.00 \%$ & $70.67 \%$ \\
A15 & $1.33 \%$ & $1.33 \%$ & $14.67 \%$ & $24.00 \%$ & $58.67 \%$ \\
\hline
\end{tabular}

For the KMO value and Bartlett sphericity test of 15 indicators, the closer the KMO value is to 1, the stronger the correlation between variables, the more suitable for factor analysis. At the same time, if the null hypothesis of sphericity test is rejected, the variables are not independent of each other, and common factors can be extracted. According to the test results, KMO value was close to 1 and $P$ value of Bartlett sphericity test was 0.000, and null hypothesis was rejected. Therefore, the indicators in Table 2 are suitable for factor analysis.

\subsection{Extraction of common factors}

Factors with eigenvalue greater than 1 were extracted by principal component analysis, and three common factors were extracted according to indicator interpretation and scree plot to obtain eigenvalue and variance contribution, as shown in Table 3. Among them, the variance contribution rate of the first factor was the largest, reaching $25.849 \%$, that of the second factor was $24.209 \%$, and that of the third factor was $12.977 \%$. Table 3 shows that the cumulative variance contribution rate of the first three common factors whose eigenvalues were greater 
TABLE 3. Eigenvalue and variance contribution.

\begin{tabular}{|c|c|c|c|c|c|c|c|c|c|}
\hline \multirow[t]{2}{*}{ Component } & \multicolumn{3}{|c|}{ Initial eigenvalue } & \multicolumn{3}{|c|}{ Extract sums of squares loadings } & \multicolumn{3}{|c|}{ Rotation sums of squared loadings } \\
\hline & Summation & Variance & Accumulation & Summation & Variance & Accumulation & Summation & Variance & Accumulation \\
\hline 1 & 6.658 & $44.384 \%$ & $44.384 \%$ & 6.658 & $44.384 \%$ & $44.384 \%$ & 3.877 & $25.849 \%$ & $25.849 \%$ \\
\hline 2 & 1.535 & $10.233 \%$ & $54.617 \%$ & 1.535 & $10.233 \%$ & $54.617 \%$ & 3.631 & $24.209 \%$ & $50.058 \%$ \\
\hline 3 & 1.263 & $8.418 \%$ & $63.035 \%$ & 1.263 & $8.418 \%$ & $63.035 \%$ & 1.947 & $12.977 \%$ & $63.035 \%$ \\
\hline 4 & .990 & $6.598 \%$ & $69.633 \%$ & & & & & & \\
\hline 5 & .791 & $5.272 \%$ & $74.906 \%$ & & & & & & \\
\hline 6 & .711 & $4.738 \%$ & $79.644 \%$ & & & & & & \\
\hline 7 & .570 & $3.800 \%$ & $83.444 \%$ & & & & & & \\
\hline 8 & .562 & $3.746 \%$ & $87.191 \%$ & & & & & & \\
\hline 9 & .466 & $3.106 \%$ & $90.296 \%$ & & & & & & \\
\hline 10 & .397 & $2.649 \%$ & $92.946 \%$ & & & & & & \\
\hline 11 & .329 & $2.195 \%$ & $95.141 \%$ & & & & & & \\
\hline 12 & .266 & $1.772 \%$ & $96.913 \%$ & & & & & & \\
\hline 13 & .207 & $1.382 \%$ & $98.295 \%$ & & & & & & \\
\hline 14 & .154 & $1.029 \%$ & $99.325 \%$ & & & & & & \\
\hline 15 & .101 & $.675 \%$ & $100.000 \%$ & & & & & & \\
\hline
\end{tabular}

Notes. Extraction method is principal component analysis.

than 1 account for $63.035 \%$, indicating that these three common factors can explain most of the information of the original indicators. Therefore, the first three main factors were used in this paper for analysis.

\subsection{Factor denomination}

In order to investigate the correlation coefficient between the common factor and each indicator, it is necessary to find out the factor load matrix, and reflect the load of the $i$ th indicator on the $j$ th common factor from each value in the matrix. The higher the load, the higher the importance of the $i$ th indicator on the $j$ th common factor. Through the rotation analysis of factor load matrix by the method of varimax rotation, the results are shown in Table 3. Table 4 shows that factor 1 has a large load on A9, A10, A15, A3, A12 and A14, reflecting

TABLE 4. Rotation component matrix table.

\begin{tabular}{|c|c|c|c|}
\hline & \multicolumn{3}{|c|}{ Component } \\
\hline & $F_{1}$ & $F_{2}$ & $F_{3}$ \\
\hline A9 & .767 & .260 & -.059 \\
\hline A10 & .760 & .413 & -.021 \\
\hline A15 & .756 & .097 & .265 \\
\hline A3 & .731 & .173 & .145 \\
\hline $\mathrm{A} 13$ & .654 & .319 & .363 \\
\hline A12 & .628 & .402 & .169 \\
\hline A14 & .620 & .095 & .427 \\
\hline A 8 & .280 & .798 & -.002 \\
\hline A 6 & .220 & .795 & .134 \\
\hline A5 & .077 & .766 & .161 \\
\hline A7 & .284 & .706 & .180 \\
\hline A11 & .163 & .598 & .289 \\
\hline $\mathrm{A} 4$ & .270 & .515 & .140 \\
\hline $\mathrm{A} 2$ & .089 & .187 & .864 \\
\hline A1 & .275 & .264 & .763 \\
\hline
\end{tabular}

Notes. Extraction method: principal component. Rotation: orthogonal rotation with Kaiser standardization. A: rotation converges after iteration 5 . The bold values means the factors have a large load in the F1, F2, or F3. In other words, they are important to F1, F2, or F3. This factor can be used to calculated the F1, F2, or F3 
environmental governance, voting democratic rights and satisfaction of neighborhood relations, which can be denominated as living environment factors; factor 2 has a large load on A8, A6, A5, A7, A11 and A4, reflecting the satisfaction of industry, living standard and cultural atmosphere, which can be denominated as life quality factors; factor 3 has a large load on A2 and A1, reflecting the degree of publicity and understanding of rural revitalization strategy, which can be denominated as publicity effect factors.

\subsection{Factor score}

Factor score is the score of common factors $F_{1}, F_{2}, F_{3}$, etc. on each indicator. It is necessary to give a linear expression of the common factor expressed by the original indicator variable. After the expression is determined, the value of the original indicator can be substituted into the expression to find the score value of each factor. Therefore, a regression equation was established with the common factor as the dependent variable and the original indicator as the independent variable:

$$
F_{j}=\beta_{j 1} X_{1}+\beta_{j 2} X_{2}+\ldots+\beta_{j 15} X_{15} .
$$

Since the original indicators and common factor variables in the equation are standardized variables, there is no constant term in the regression equation, and the scores of each factor can be calculated according to the equation. Table 5 shows the component score coefficient matrix $t$.

\subsection{Factor score evaluation}

The comprehensive factor scores of each village can be obtained by the formula in Table 5 :

$$
F=\left(0.25849 * F_{1}+0.24209 * F_{2}+0.12977 * F_{3}\right) / 0.63035
$$

that is,

$$
F=0.410 * F_{1}+0.384 * F_{2}+0.206 * F_{3} .
$$

According to the scores of the villagers in the village, the values were calculated and sorted, as shown in

\begin{tabular}{|c|c|c|c|}
\hline & \multicolumn{3}{|c|}{ Component } \\
\hline & $F_{1}$ & $F_{2}$ & $F_{3}$ \\
\hline A1 & -.060 & -.045 & .461 \\
\hline A2 & -.141 & -.054 & .573 \\
\hline A3 & .257 & -.096 & -.039 \\
\hline A4 & -.014 & .156 & -.016 \\
\hline A5 & -.154 & .306 & -.004 \\
\hline A6 & -.094 & 293 & -.051 \\
\hline A7 & -.055 & 233 & -.016 \\
\hline A 8 & -.046 & .301 & -.158 \\
\hline A9 & .287 & -.036 & -.202 \\
\hline A10 & .246 & .029 & -.195 \\
\hline A11 & -.102 & .195 & .096 \\
\hline A12 & .160 & .025 & -.037 \\
\hline A13 & .158 & -.044 & .107 \\
\hline A14 & .180 & -.147 & .190 \\
\hline A15 & .264 & -.152 & .052 \\
\hline
\end{tabular}
Table 6. Table 6 shows that the living environment factor $F_{1}$ of Xiashantou Village in Dajing Town, Xinger

TABLE 5. Component score coefficient matrix table.

Notes. Extraction method: principal component. Rotation: orthogonal rotation with Kaiser standardization. 
TABLE 6. Average score and ranking of each factor in each village.

\begin{tabular}{lccccccccc}
\hline \hline $\begin{array}{l}\text { Village } \\
\text { name }\end{array}$ & $\begin{array}{c}\text { Number of } \\
\text { questionnaires }\end{array}$ & $\begin{array}{c}F_{1} \\
\text { average }\end{array}$ & $\begin{array}{c}F_{1} \\
\text { sorting }\end{array}$ & $\begin{array}{c}F_{2} \\
\text { average }\end{array}$ & $\begin{array}{c}F_{2} \\
\text { sorting }\end{array}$ & $\begin{array}{c}F_{3} \\
\text { average }\end{array}$ & $\begin{array}{c}F_{3} \\
\text { sorting }\end{array}$ & $\begin{array}{c}F \\
\text { average }\end{array}$ & $\begin{array}{c}F \\
\text { sorting }\end{array}$ \\
\hline Dongfeng & 14 & 0.180 & 3 & 0.428 & 2 & 0.293 & 2 & 0.299 & 1 \\
Xiashantou & 26 & 0.241 & 1 & 0.486 & 1 & -0.342 & 6 & 0.215 & 2 \\
Fenghuang & 26 & -0.156 & 5 & 0.293 & 3 & 0.439 & 1 & 0.139 & 3 \\
Xinger & 30 & 0.181 & 2 & -0.087 & 5 & -0.063 & 3 & 0.028 & 4 \\
Tuduntang & 22 & -0.289 & 6 & 0.217 & 4 & -0.110 & 5 & -0.058 & 5 \\
Xianshengmen & 32 & -0.119 & 4 & -0.888 & 6 & -0.071 & 4 & -0.404 & 6 \\
\hline
\end{tabular}

Notes. The score of each factor, plus or minus, only represents the relative position score of the village under the investigation level of this factor and the average level of this factor. A positive score means higher than the average level, while a negative score means lower than the average.

Village in Nanyue Town and Dongfeng Village in Liushi Town are higher than the average level, while that of Tuduntang Village in Chengdong Sub-district is relatively poor. Except Xinger Village in Nanyue Town and Xianshengmen Village in Longxi Township, the life quality factor $F_{2}$ of the other four villages is higher than the average level, and the gap between Xianshengmen Village in Longxi Township and other villages is large, which needs to be strengthened. The publicity effect factor $F_{3}$ of Fenghuang Village in Baishi Sub-street and Dongfeng Village in Liushi Town in is above the average level, and the gap between Xiashantou Village and other villages in Dajing Town is large. In consideration of the comprehensive score of rural revitalization strategy, the six villages are ranked as Dongfeng Village in Liushi Town, Xiashantou Village in Dajing Town, Fenghuang Village in Baishi Sub-street, Xinger Village in Nanyue Town, Tuduntang Village in Chengdong Sub-street and Xianshengmen Village in Longxi Township, with the exception of Tuduntang Village and Xianshengmen Village, the other four villages are all above the average level. However, for Tuduntang Village, its deficiencies in living environment factor $F_{1}$ and publicity effect factor $F_{3}$ can be improved from environmental governance, voting democratic rights, satisfaction of neighborhood relations and publicity of rural revitalization strategy. For Xianshengmen Village whose three factors are below the average level, the lack of life quality factor $F_{2}$ is very prominent which can be improved from the industry, living standards, cultural atmosphere, effectively implementing the rural revitalization strategy, accelerating the modernization of agricultural and rural areas, fundamentally solving the problems of agricultural and rural farmers, and realizing the grand blueprint of rural revitalization step by step.

\section{EMPIRICAL TEST OF THE EFFECT OF FINANCIAL INCLUSION ON RURAL REVITALIZATION: A QUANTITATIVE ANALYSIS BASED ON MULTIPLE LINEAR REGRESSION}

In order to explore the extent of financial inclusion promoting rural revitalization from the perspective of considerable data, the team plans to take the living environment factor $F_{1}$, life quality factor $F_{2}$, publicity effect factor $F_{3}$ and the comprehensive factor $\mathrm{F}$ in the evaluation system of rural revitalization strategy as explanatory variables to measure the implementation effect of rural revitalization. By analyzing and comparing different financial inclusion indicator systems, Xia Gao [4] evaluated their respective advantages and disadvantages, and concluded that to analyze China's economic and financial situation in the 21 st century, it is necessary to analyze from three dimensions: the quality of formal financial services, the use and the availability of financial services [6]. Therefore, in this questionnaire, loan convenience, micro credit impact and the number of basic financial service outlets were selected as the core explanatory variables to measure the financial inclusion, corresponding to the above three dimensions respectively, and gender, age, personal monthly income, number of families, whether to use smart phones, smoking or not, and life happiness were selected as control variables to establish a multiple linear regression model to explore the impact of financial inclusion on promoting the rural revitalization. 
TABLE 7. Variables.

\begin{tabular}{|c|c|c|c|}
\hline $\begin{array}{l}\text { Variable } \\
\text { categories }\end{array}$ & Variables & Variable meaning & Variable value \\
\hline \multirow{3}{*}{$\begin{array}{l}\text { Core } \\
\text { explanatory } \\
\text { variable }\end{array}$} & $\mathrm{cbl}$ & Convenient bank loan & $\begin{array}{l}1=\text { "Not clear"; } \quad 2=\text { "Not convenient"; } \\
3=\text { "Convenient" }\end{array}$ \\
\hline & mlilc & $\begin{array}{l}\text { Microloan has improved the living con- } \\
\text { ditions in the village }\end{array}$ & $\begin{array}{l}1=\text { "No"; } 2=\text { "The same as not having } \\
\text { microloan"; } 3=\text { "Improved a little bit"; } \\
4=\text { "Greatly improved" }\end{array}$ \\
\hline & mwp & $\begin{array}{l}\text { Yueqing rural bank has more with- } \\
\text { drawal points than other banks }\end{array}$ & $\begin{array}{l}1=\text { "Totally disagree"; } 2=\text { "not quite agree"; } \\
3=\text { "Neutral opinion"; } 4=\text { "quite agree"; } \\
5=\text { "totally agree" }\end{array}$ \\
\hline \multirow{7}{*}{$\begin{array}{l}\text { Control } \\
\text { variable }\end{array}$} & Gender & - & $1=$ "Male"; $2=$ "Female" \\
\hline & Age & - & - \\
\hline & pmi & Personal monthly income & - \\
\hline & $\mathrm{fn}$ & Family number & - \\
\hline & & Can you use smartphone? & $1=$ "Can"; $2=$ "Cannot" \\
\hline & Smoke & Do you smoke? & $1=" Y e s " ; 2=$ "No" \\
\hline & hl & Think life is happy now & $\begin{array}{l}1=\text { "Totally disagree"; } 2=\text { "not quite agree"; } \\
3=\text { "Neutral opinion"; } 4=\text { "quite agree"; } \\
5=\text { "totally agree" }\end{array}$ \\
\hline \multirow{4}{*}{$\begin{array}{l}\text { Explained } \\
\text { variable }\end{array}$} & $F_{1}$ & Living environment factor & - \\
\hline & $F_{2}$ & Life quality factor & - \\
\hline & $F_{3}$ & Publicity effect factor & - \\
\hline & $F$ & Comprehensive factor & $\begin{array}{l}\text { Calculated according to the equation in } \\
\text { Section } 4.4\end{array}$ \\
\hline
\end{tabular}

The multiple linear equation established is shown in equation (5.1).

$$
F_{j}=\alpha_{j}+\beta_{j 1} c b l+\beta_{j 2} m l i l c+\beta_{j 3} m w p+\beta_{j 4} \text { control }+u .
$$

$F$ is a matrix composed of the convenience of bank loans, the promotion of micro credit to the living standard of the village and the number of withdrawal outlets as the core explanatory variables, and the control variables such as gender, age, personal monthly income, number of families, whether to use smart phones, smoking or not and life happiness The specific variable names and meanings are shown in Table 7.

From the regression results (see Tab. 8), in the living environment factor equation, the loan convenience is significant at the confidence level of 1 , and the impact of micro credit, smoking or not and age are significant at the confidence level of $10 \%$, indicating that the more convenient it is to borrow from banks, the more significant it is to improve the living standard of the village and the scores of the living environment factors of the non-smoking and the elderly.

In the life quality factor equation, the number of withdrawal outlets is significant at the confidence level of 1 , the degree of loan convenience and age are significant at the level of $5 \%$, the impact of micro credit, whether to use smart phones, smoking or not, and life happiness are significant at the level of $10 \%$, which indicates that the more convenient the loan and the more the withdrawal outlets are in the financial inclusion mode, the more people will feel that their life is very happy subjectively, and that that the use of smart phones and the increase of age can significantly improve the scores of life quality factors. However, it is found that the correlation coefficient of loan convenience in the equation of life quality factor is negative. According to the analysis, the local electrical manufacturing and mold production industries are developed. After obtaining the loan, most residents tend to invest the loan in these two industries which are easy to have a negative impact on the environment. Therefore, the indicator of loan convenience is negatively related to the quality of life. 
TABLE 8. Regression result.

\begin{tabular}{|c|c|c|c|c|}
\hline & $F_{1}$ & $F_{2}$ & $F_{3}$ & $F$ \\
\hline cbl & $\begin{array}{l}0.650^{* * *} \\
(0.181)\end{array}$ & $\begin{array}{c}-0.354^{* *} \\
(0.162)\end{array}$ & $\begin{array}{c}0.323 \\
(0.195)\end{array}$ & $\begin{array}{l}0.197^{* *} \\
(0.096)\end{array}$ \\
\hline mlilc & $\begin{array}{c}0.296^{*} \\
(0.167)\end{array}$ & $\begin{array}{c}0.259^{*} \\
(0.150)\end{array}$ & $\begin{array}{c}0.067 \\
(0.180)\end{array}$ & $\begin{array}{l}0.235^{* *} \\
(0.089)\end{array}$ \\
\hline mwp & $\begin{array}{c}0.031 \\
(0.132)\end{array}$ & $\begin{array}{l}0.394^{* * *} \\
(0.118)\end{array}$ & $\begin{array}{c}-0.104 \\
(0.142)\end{array}$ & $\begin{array}{l}0.142^{* *} \\
(0.070)\end{array}$ \\
\hline Gender & $\begin{array}{c}0.549^{*} \\
(0.328)\end{array}$ & $\begin{array}{c}-0.060 \\
(0.294)\end{array}$ & $\begin{array}{c}-0.111 \\
(0.353)\end{array}$ & $\begin{array}{c}0.179 \\
(0.174)\end{array}$ \\
\hline age & $\begin{array}{c}-0.003 \\
(0.010)\end{array}$ & $\begin{array}{l}0.026^{* * *} \\
(0.009)\end{array}$ & $\begin{array}{c}0.003 \\
(0.011)\end{array}$ & $\begin{array}{c}0.010^{*} \\
(0.006)\end{array}$ \\
\hline pmi & $\begin{array}{r}-0.054 \\
(0.068)\end{array}$ & $\begin{array}{c}0.070 \\
(0.061)\end{array}$ & $\begin{array}{c}-0.041 \\
(0.074)\end{array}$ & $\begin{array}{r}-0.003 \\
(0.036)\end{array}$ \\
\hline fn & $\begin{array}{c}-0.032 \\
(0.079)\end{array}$ & $\begin{array}{c}0.005 \\
(0.071)\end{array}$ & $\begin{array}{r}-0.039 \\
(0.085)\end{array}$ & $\begin{array}{r}-0.019 \\
(0.042)\end{array}$ \\
\hline $\mathrm{sp}$ & $\begin{array}{c}0.101 \\
(0.391)\end{array}$ & $\begin{array}{r}-0.635^{*} \\
(0.351)\end{array}$ & $\begin{array}{r}-0.196 \\
(0.422)\end{array}$ & $\begin{array}{c}-0.242 \\
(0.208)\end{array}$ \\
\hline hl & $\begin{array}{c}0.059 \\
(0.178)\end{array}$ & $\begin{array}{c}0.292^{*} \\
(0.159)\end{array}$ & $\begin{array}{c}0.266 \\
(0.192)\end{array}$ & $\begin{array}{l}0.191^{* *} \\
(0.095)\end{array}$ \\
\hline Smoke & $\begin{array}{r}-0.521^{*} \\
(0.275)\end{array}$ & $\begin{array}{c}-0.049 \\
(0.247)\end{array}$ & $\begin{array}{c}0.153 \\
(0.297)\end{array}$ & $\begin{array}{c}-0.201 \\
(0.147)\end{array}$ \\
\hline _cons & $\begin{array}{c}-3.859^{* * *} \\
(1.371)\end{array}$ & $\begin{array}{c}-2.906^{* *} \\
(1.230)\end{array}$ & $\begin{array}{r}-2.105 \\
(1.480)\end{array}$ & $\begin{array}{l}-3.132^{* * *} \\
(0.729)\end{array}$ \\
\hline $\operatorname{adj} . R^{2}$ & 0.145 & 0.313 & 0.005 & 0.324 \\
\hline
\end{tabular}

Notes. () is the standard deviation; ${ }^{*} p<0.10,{ }^{* *} p<0.05,{ }^{* * *} p<0.01$; It should be noted that, due to the relatively small number of samples obtained in this study, the highest confidence level we selected was $10 \%$, but the established model still had strong explanatory ability.

In the publicity effect factor equation, only the loan convenience is significant at the confidence level of $10 \%$, which can weakly explain that the more convenient it is to borrow from banks, the more significant it is to improve the score of publicity effect factor.

In the comprehensive factor equation of rural revitalization policy implementation, the effect of micro credit is significant at the confidence level of $1 \%$. The degree of loan convenience, the number of withdrawal outlets and the life happiness are significant at the confidence level of $5 \%$. The age is significant at the confidence level of $10 \%$. The result indicates the more convenient bank loans, more withdrawal outlets and more elderly people are, the more subjective micro credit improves the living standard of the village and the more subjective they feel that the present life is very happy, which can significantly improve the overall factor score of rural revitalization policy implementation.

From the above analysis results, it can be concluded that the three selected explanatory variables of quantitative financial inclusion can significantly and positively affect the comprehensive factor score of rural revitalization strategy implementation at the confidence levels of $5 \%, 1 \%$ and $5 \%$, respectively. It is thus clear that the implementation of financial inclusion can positively promote the implementation of rural revitalization strategy. Specifically, the impact of financial inclusion on rural revitalization has different emphases in three aspects: living environment, life quality and publicity effect. The living environment is mainly affected by the convenience of loans, satisfaction, smoking and other pollution, the life quality is mainly affected by material improvement and subjective well-being, and the publicity effect is mainly affected by financial popularization and use efficiency. According to their own actual situation, each village can promote the overall upgrading of agriculture, the overall progress of rural areas and the overall development of farmers, and write a new chapter 
in the overall revitalization of rural areas in the new era with greater determination, clearer objectives and more powerful measures.

\section{Summary AND POLiCy IMPlications}

The financial inclusion has achieved industrial prosperity, ecological livability, rural civilization and effective governance respectively through the mode of village credit granting and low interest loan, environmental improvement and targeted loan, model publicity and moral loan, "harvest station" and platform cooperation, which react on the affluence of life, and finally realize the rural revitalization. Based on the factor analysis of the rural revitalization strategy evaluation scale, an evaluation system including three factors of living environment, quality of life and publicity effect was established. The multiple linear regression was carried out on the basis of this evaluation system. Finally, it is concluded that financial inclusion can actively promote the implementation of rural revitalization strategy. Among them, the mode of rural revitalization promoted by financial inclusion in Yueqing area could significantly promote the living environment and quality of life in the content of rural revitalization. The regression results showed that although the mode could promote the publicity effect, the effect was not significant. The living environment of villagers is closely related to the convenience of loans and the satisfaction of micro credit; besides the above two factors, the number of withdrawal outlets also affects the quality of life of villagers. These three factors together affect the overall effect of the implementation of the rural revitalization policy. To sum up, the deficiencies in publicity effect should be made up actively in the mode of rural revitalization promoted by financial inclusion in Yueqing, such as publicizing the connotation of rural revitalization to villagers and teaching basic financial knowledge.

Aiming at some problems of mode of rural revitalization promoted by financial inclusion in Yueqing, some policy suggestions are put forward for reference in this paper starting from the connotation of rural revitalization. In order to promote the prosperity of the industry, the main industries in Yueqing rural areas are agriculture and electrical manufacturing. For agriculture, the upgrading of agricultural industry needs to be actively promoted to form a perfect agricultural industry chain. For the electrical manufacturing industry, it is necessary to control the harm to the environment while increasing production investment so as to achieve sustainable development. In view of the ecological livability and rich ecological natural resources, Yueqing should respect and comply with the nature, develop the natural ecological landscape appropriately and selectively, take the ecological environment as the catalyst of rural revitalization, and follow the principle of "lucid waters and lush mountains are invaluable assets". In terms of rural civilization, the construction of cultural auditorium should be strongly supported, focusing on the protection of local cultural traditions and customs in Yueqing, actively promoting the education and publicity of financial knowledge, so that everyone can be facilitated truly by financial inclusion. In the aspect of effective governance, the model of harvest stations as government agencies should be adhered to, and various incentive means should be introduced to encourage grass-roots autonomy. In the aspect of living well-off, the mode of "leading some people to become rich first and then bringing along the poorer" should be strongly called on to encourage the regurgitation-feeding of rural areas.

Acknowledgements. The study was supported by Zhejiang province philosophy social science planning project(20NDJC134YB); National Natural Science Foundation Project of China (71773108). Zhejiang Natural Science Fund Project (LY17G030023); Zhejiang province human resources and social security scientific research project (2019038) and Graduated students' field survey project by Zhejiang University of Finance and Economic.

\section{REFERENCES}

[1] G.T. Abate, S. Rashid, C. Borzaga and K. Getnet, Rural finance and agricultural technology adoption in Ethiopia: Does the institutional design of lending organizations matter? World Dev. 84 (2016) 235-253.

[2] M. Chen, C. Liao and T. Liu, Rural revitalization, collective economic organization and land use system innovation: Based on analysis of Huangxi village, Jiangxi province. J. Nanjing Agric. Univ. 2 (2018) 27-34.

[3] Y. Chen, G. Wang and W. Sun, Agricultural Status and Agricultural Development in the Rural Revitalization Strategy. Issues Agric. Econ. 1 (2018) 20-26. 
[4] X. Gao, Contemporary Financial Inclusion Theory and Relevant Countermeasures in China. Liaoning University, Lianoning (2016).

[5] Z. Huang, On the strategy of rural revitalization in China. Chin. Rural Econ. 4 (2018) 2-12.

[6] Institute of financial strategy, CASS, China's County Economic Development Report. Available at: http://www.eeo.com.cn/ 2018/1204/342597.shtml (December 2018), in Chinese [Accessed November 3, 2019].

[7] Y. Li, P. Fan and Y. Liu, What makes better village development in traditional agricultural areas of China? Evidence from long-term observation of typical villages. Habitat Int. 83 (2019) 111-124.

[8] D. Lv, 70 years of rural governance: a perspective of the modernization of state governance. J. Nanjing Agric. Univ. 19 (2019) 11-19.

[9] W. Martha, The politics of local government performance: Elite cohesion and cross-village constraints in decentralized Senegal. World Dev. 103 (2018) 149-161.

[10] People's daily, The Speech of Xi Jinping at the Nineteenth National Congress of the Communist Party of China. Available at: http://cpc.people.com.cn/n1/2017/1028/c64094-29613660-7.html (October 2017), in Chinese [Accessed November 3, 2019].

[11] People's daily, Make Financial Inclusion an Important Role. Available at: http://theory·people.com.cn/GB/n1/2019/0510/ c40531-31076853.html (May 2019), in Chinese [Accessed November 3, 2019].

[12] Y. Shen, J. Li and J. Yang, Research on poverty reduction mechanism based on Financial Credit for Agricultural supply chain in the background of Rural revitalization, from the perspective of Peasant Households ability to eliminate poverty. J. Southwest Univ. 45 (2019) 50-60.

[13] The State Council, The Plan for Promoting Inclusive Financial Development (2016-2020). Available at: http://www.gov.cn/ zhengce/content/2016-01/15/content_10602.htm (December 2015), in Chinese [Accessed November 3, 2019].

[14] The Xinhua News Agency, Opinions of the Central Committee of the Communist Party of China and the State Council on the implementation of the strategy of Rural Revitalization. Available at: http://www.gov.cn/zhengce/2018-02/04/content_ 5263807.htm (February 2018), in Chinese [Accessed November 3, 2019].

[15] P. Xu, The cultural construction of the new socialist countryside, Sci. Soc. 1 (2006) 56-59.

[16] H. Yang, Practice, challenge and countermeasure of financial support to rural revitalization - based on investigation and thinking in Ganzhou. J. Finance Econ. 2 (2019) 60-64.

[17] X. Yang, The exploration of values in rural revitalization in Japan: A case study of Noto's Satoyama and Satoumi. Urban Planning Int. 5 (2016) 115-120.

[18] Yueqing Government Information Catalogue, National economic and social development statistics bulletin of Yueqing in 2018. Available at: http://xxgk. yueqing.gov.cn/art/2019/3/27/art_1345559_31695655.html (March 2019), in Chinese [Accessed November 3, 2019].

[19] F. Zeng and B. Cai, Realizing the rural vitalization strategy of Human by promoting rural industrialization. Res. Agric. Mod. 39 (2018) 179-184.

[20] F. Zeng and B. Cai, Rural Infrastructure Is the Basis of the Rural Vitalization Strategy. Issues Agric. Econ. 7 (2018) 88-95.

[21] J. Zhang, Village value orientation and rural revitalization. Chin. Rural Economy 1 (2018) 2-9.

[22] C. Zhu, The exploration of inclusive finance in Zhejiang. Chin. Finance 23 (2016) 9-10. 